Tropical Journal of Pharmaceutical Research September 2020; 19 (9): 1887-1893

ISSN: $1596-5996$ (print); 1596-9827 (electronic) (C) Pharmacotherapy Group, Faculty of Pharmacy, University of Benin, Benin City, 300001 Nigeria.

\title{
Gastroprotective effect of the root extract of Alpinia officinarum Hance (Zingiberoside) against acute indomethacin-induced gastric injuries in rats: Involvement of $\mathrm{H}+/ \mathrm{K}+-A T P a s e$ and prostaglandin $E$ receptors
}

\author{
Jingwen Gong, Xuguang Zhang, Yinfeng Tan, Hailong Li, Jie Hou*, Junqing \\ Zhang* \\ Key Laboratory of Tropical Translational Medicine of Ministry of Education, Hainan Provincial Key Laboratory for Research and \\ Development of Tropical Herbs, School of Pharmacy, Hainan Medical University, Haikou, China
}

*For correspondence: Email: houjiede20066@163.com, jqzhang2011@163.com; Tel: +86-898-66893826, +86-898-66895337

Sent for review: 22 April 2020

Revised accepted: 24 August 2020

\begin{abstract}
Purpose: To investigate the protective effects of Alpinia officinarum root ethanol extract (AOE) and galangin against acute indomethacin-induced injury on rat gastric mucosa

Methods: Sprague-Dawley rats were daily treated with bismuth potassium citrate $(0.08 \mathrm{~g} / \mathrm{kg}), A O E$ at doses of 0.09, 0.18 and $0.36 \mathrm{~g} / \mathrm{kg}$; and galangin $(0.2 \mathrm{~g} / \mathrm{kg})$ for 15 days. Then, gastric injury on rats was induced by intragastric administration of indomethacin $(30 \mathrm{mg} / \mathrm{kg})$. Blood flow and thickness of gastric mucosa were determined using neutral red clearance test and Alcian blue staining. The activity of $\mathrm{H}+/ K+-A T P a s e$ was assayed using a biochemical kit. Prostaglandin E receptor expressions were assayed by western blotting.

Results: High doses of ethanol extract of Alpinia officinarum root significantly inhibited $\mathrm{H}+/ \mathrm{K}+-\mathrm{ATPase}$ activity by $8.12 \%(p<0.01)$, increased gastric mucosal blood flow $(p<0.001)$, enhanced mucus thickness $(p<0.05)$, and elevated the activities of prostaglandin $E$ receptors 1 and $4(p<0.05)$. Galangin significantly inhibited $H+/ K+-A T P a s e$ activity by $4.82 \%(p<0.05)$ and increased gastric mucosal blood flow $(p<0.01)$.

Conclusion: The ethanol extract of Alpinia officinarum root attenuates indomethacin-induced gastric injury by reinforcing gastric mucosal barrier and inhibiting excessive gastric acid secretion. Thus, the extract can be potentially developed for management of gastric injuries.
\end{abstract}

Keywords: Galangin, Gastric mucosal barrier, Gastric acid, Prostaglandin, Indomethacin

\begin{abstract}
This is an Open Access article that uses a fund-ing model which does not charge readers or their institutions for access and distributed under the terms of the Creative Commons Attribution License (http://creativecommons.org/licenses/by/4.0) and the Budapest Open Access Initiative (http://www.budapestopenaccessinitiative.org/read), which permit unrestricted use, distribution, and reproduction in any medium, provided the original work is properly credited.

Tropical Journal of Pharmaceutical Research is indexed by Science Citation Index (SciSearch), Scopus, International Pharmaceutical Abstract, Chemical Abstracts, Embase, Index Copernicus, EBSCO, African Index Medicus, JournalSeek, Journal Citation Reports/Science Edition, Directory of Open Access Journals (DOAJ), African Journal Online, Bioline International, Open-J-Gate and Pharmacy Abstracts
\end{abstract}

\section{INTRODUCTION}

The worldwide use of nonsteroidal antiinflammatory drugs (NSAIDs) has increased the incidence of gastric injury $[1,2]$. It is generally known that reinforcing gastric mucosal barrier and inhibiting excessive gastric acid secretion are crucial strategies in ameliorating gastric ulcer induced by NSAIDs [3]. Prostaglandin $\mathrm{E}_{2}$ (EP) receptors are closely related to the regulation of 
mucosal defense and vascular perfusion [4]. Gastric acid secretion is closely associated with the hydrogen/potassium-adenosine triphosphatase $\left(\mathrm{H}^{+} / \mathrm{K}^{+}\right.$-ATPase $)$[5]. Thus, maintenance of activities of prostaglandin $E_{2}$ receptors while attenuating $\mathrm{H}^{+} / \mathrm{K}^{+}$-ATPase activity have become important therapeutic strategies in the treatments of gastrointestinal ulcers or gastroesophageal reflux disease.

In a previous study, it was reported that the Alpinia officinarum Hance (Zingiberoside family) root extract (AOE) markedly reversed gastric injury caused by indomethacin by increasing COX-1 activity while inhibiting COX-2 activity [6]. The ameliorated gastric mucus conditions and markedly increased VEGF levels in AOE treatment group led to a hypothesis that $A O E$ may also reinforce the gastric mucosal barrier by increasing gastric blood flow and maintaining mucosal integrity via prostaglandin $E_{2}$ receptors. Furthermore, some flavonoids, like baicalein, myricetin, and flavonoid-rich extracts have been reported to inhibit $\mathrm{H}^{+} / \mathrm{K}^{+}$-ATPase activity [7-9]. Moreover, AOE is rich in flavonoids with $11.8 \%$ galangin and $2.3 \%$ kaempferide. Therefore, another hypothesis was developed that AOE may decrease gastric acid secretion. by inhibiting $\mathrm{H}^{+} / \mathrm{K}^{+}$-ATPase activity.

To get a better understanding of the gastroprotective mechanisms of AOE, an indomethacin-induced acute gastric damage rat model was established. In this model, AOE was given to healthy rats for 15 consecutive days before indomethacin treatment. Blood flow and gastric mucus thickness were evaluated, in addition to assay of activity of $\mathrm{H}^{+} / \mathrm{K}^{+}$-ATPase and expressions of EP receptors.

\section{EXPERIMENTAL}

\section{Agents and drugs}

The ethanol extract of roots of Alpinia officinarum prepared in the authors' laboratory contained five major constituents: $21.1 \%$ DPHC (cas: 2419201-6), 20.3\% DPHA (cas: 68622-73-1), 11.8\% galangin, $5.1 \%$ DPHB (cas: 79559-60-7) and 2.3 $\%$ kaempferide [6]. Indomethacin and bismuth potassium citrate group were purchased from Sigma-Aldrich. Galangin was bought from Pufei De Biotech Co. Ltd (Chengdu, China).

\section{Experimental animals}

Sprague-Dawley (SD) rats weighting 190 - $210 \mathrm{~g}$ were purchased from Tianqing Biotechnology (Changsha, China), and they were acclimatized to the animal house conditions (12 h light/dark cycle, $25-26{ }^{\circ} \mathrm{C}$ temperature) for 7 days, prior to commencement of the study. All animal experiments were performed under the guidelines of the Care and Use of Laboratory Animals [10], with the approval of the animal ethics committee of Hainan Medical University (Reg. no. 201812023/HMU).

\section{Drug treatment}

Forty-two SD rats of both sexes were randomly assigned to seven groups: high, medium and low AOE groups (AOE-H, $0.36 \mathrm{~g} / \mathrm{kg}$; AOE-M, 0.18 $\mathrm{g} / \mathrm{kg}$ and AOE-L, $0.09 \mathrm{~g} / \mathrm{kg}$ ); galangin group (GAL, $0.2 \mathrm{~g} / \mathrm{kg}$ ); bismuth potassium citrate group (POS, $0.08 \mathrm{~g} / \mathrm{kg}$ ); control group (CON) and indomethacin group (MOD, $30 \mathrm{mg} / \mathrm{kg}$ ). The drugs were intragastrically administrated to the rats once a day for 15 days, while equivalent volumes of vehicle were administered to rats in CON and MOD groups. Gastric injury was induced using indomethacin $12 \mathrm{~h}$ after drug administrations on day 15 , while the CON group was administered vehicle. The vehicle was $1 \%(\mathrm{w} / \mathrm{v})$ sodium carboxymethyl cellulose containing $2 \% \quad(\mathrm{w} / \mathrm{v})$ glycerol, and it was given at a dose of $2.5 \mathrm{~mL} / \mathrm{kg}$ body weight.

\section{Neutral red clearance test}

One hour after indomethacin was given, each rat was anesthetized with urethane and a gastric fistula was made. Then, using a micro infusion pump, neutral red $(5 \mathrm{mg} / \mathrm{ml})$ was injected through the right femoral vein at the rate of $3 \mathrm{mg} / \mathrm{kg} / \mathrm{h}$ for $5 \mathrm{~min}$. Then the concentration of neutral red was changed to $0.5 \mathrm{mg} / \mathrm{ml}$, and the injection through the femoral vein was continued at the same rate (3 mg/kg/h). The gastric juice was washed away with normal saline at the first hour. Then, the pumping was continued for another $3 \mathrm{~h}$. Each rat was sacrificed at the end of the third hour, and 1 $\mathrm{mL}$ blood was collected through heart puncture. The blood was injected into a test tube containing $0.1 \mathrm{~mL}$ of $0.1 \mathrm{M} \mathrm{NaOH}$, followed by addition of $10 \mathrm{~mL}$ of ethyl ether. The mixture was vortexed and allowed to stand for $10 \mathrm{~min}$. Then, $2 \mathrm{~mL}$ of $0.1 \mathrm{M} \mathrm{HCl}$ was added to the supernatant, and the mixture was vortexed and left to stand for $10 \mathrm{~min}$.

Each rat stomach was completely removed into a $50 \mathrm{ml}$ centrifuge tube. The gastric juice was collected via centrifugation at $3000 \mathrm{rpm}$ for 10 $\mathrm{min}$, and then filtered. The gastric juice was treated in the same way as blood as indicated above, except that the volumes of $0.1 \mathrm{M} \mathrm{NaOH}$ and $0.1 \mathrm{M} \mathrm{HCl}$ were 0.5 and $4 \mathrm{~mL}$, respectively. The absorbances of all samples were read at $540 \mathrm{~nm}$ in a spectrophotometer against $0.1 \mathrm{M}$ 
$\mathrm{HCl}$ which was used as blank.

The amounts of neutral red in the gastric juice and serum was obtained from a neutral red standard curve, and the gastric mucosal blood flow (GMBF) was calculated as in Eq 1.

GMBF $(\mathrm{mL} / \mathrm{kg} / \mathrm{h})=2 \mathrm{G} /[(\mathrm{B}-\mathrm{b}) \times 3 \mathrm{~W}$

where $G$ stands for neutral red concentration of gastric juice, $W$ stands for rat body weight, (B-b) stands for neutral red concentration in serum, and $b$ is a constant calculated from five different blank rat sera under the same treatment.

\section{Determination of gastric mucus}

The opened rat stomach was immersed in $0.1 \%$ Alcian blue solution (10 $\mathrm{mL} / \mathrm{sample})$ and incubated for $2 \mathrm{~h}$. Then, the segments were washed for $1 \mathrm{~h}$ with $0.25 \mathrm{M}$ sucrose so as to remove excess dye. Thereafter, the segments were immersed in $0.5 \mathrm{M} \mathrm{MgCl}_{2}$ for $2 \mathrm{~h}$ to extract the mucus-dye complex. The dye extract was mixed with diethyl ether, and the mixture was centrifuged at $3500 \mathrm{rpm}$ for $10 \mathrm{~min}$. The absorbance of the supernate was read at $598 \mathrm{~nm}$ in a spectrophotometer. The results were extrapolated from an Alcian blue standard curve, and presented as $\mu \mathrm{g}$ Alcian blue / $\mathrm{g}$ tissue.

\section{Assay $\mathrm{H}^{+} / \mathrm{K}^{+}$-ATPase activity}

The glandular segments were weighed and a 10 $\%$ tissue homogenate solution was prepared in normal saline. The homogenate was centrifuged at $2500 \mathrm{rpm}$ for $10 \mathrm{~min}$, and the supernate was diluted to $2 \%$ with normal saline. The $\mathrm{H}^{+} / \mathrm{K}^{+}$ATPase activity of each sample was assayed using a biochemical kit (First Division of Nanjing Jiancheng Bioengineering Research Institute, A069). The enzymatic reaction and the phosphorus determination reaction were performed following the manufacturer's instructions. At the end of the reactions, the solutions were cooled to $25^{\circ} \mathrm{C}$, and absorbance was measured at $660 \mathrm{~nm}$ using a microplate reader.

\section{Western blot analysis of EP receptors}

The mucosal tissue proteins were extracted and uniform concentrations of proteins were fractionated with $10 \%$ SDS-PAGE, and transferred to PVDF membranes. The membranes were blocked with $5 \%$ skim milk for $1.5 \mathrm{~h}$ and subsequently probed overnight at $4^{\circ} \mathrm{C}$ with the primary antibodies against EP-1 (1:1000, ThermoFisher, PA5-76888), EP-2 (1:2000, Abcam. ab167171), EP-3 (1:2000,
ThermoFisher, MA1-12647), EP-4 (1:2000, Santa, sc-55596) and $\beta$-actin (1:3000, Abcam, ab8226). Thereafter, the membranes were incubated with secondary antibody at $25^{\circ} \mathrm{C}$ for 1.5 h. A Bio-Rad ChemiDoc XRS+ chemiluminescence image analysis system was used to analyze the band densities.

\section{Statistical analysis}

The data are expressed as mean \pm SEM, and they were compared using One-way ANOVA or Kruskal-Wallis $H$ test. Values of $p<0.05$ were considered statistically significant.

\section{RESULTS}

\section{AOE and galangin increased gastric} mucosal blood flow

As shown in Figure 1, GMBF was increased significantly in rats treated with $\mathrm{AOE}$ or bismuth potassium citrate $(p<0.001)$, when compared with the MOD group. Galangin showed less effect on GMBF $(p<0.01)$, when compared with the MOD group. Only GAL $(p<0.01)$ and MOD $(p<0.001)$ groups differed significantly from the CON group, indicating that GMBFs in the other groups were protected by the pretreatments with AOE and bismuth potassium citrate.

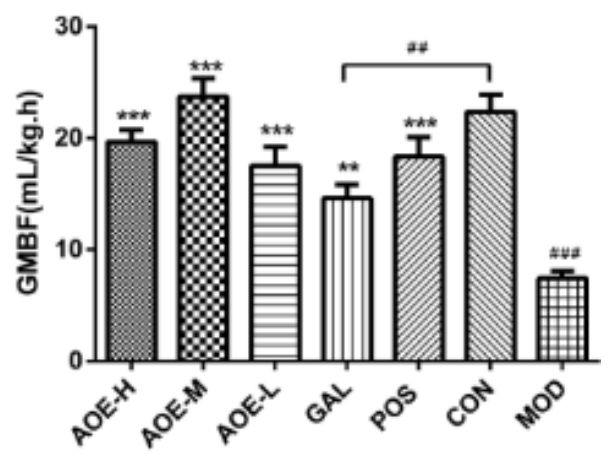

Figure 1: Effect of $A O E$ and galangin on the GMBF in acute indomethacin-induced gastric injury rat model. ${ }^{\# \#} P<0.01$, \#\#\# $p<0.001$, vs CON group; ${ }^{* *} p<0.01,{ }^{* * *} p$ $<0.001$, vs MOD group

AOE, but not galangin, increased gastric mucus thickness

The tissue value of Alcian blue was $0.58 \pm 0.05$ $\mu \mathrm{g} / \mathrm{g}$ in MOD group, $0.88 \pm 0.11 \mu \mathrm{g} / \mathrm{g}$ in POS group, $0.88 \pm 0.10 \mu \mathrm{g} / \mathrm{g}$ in AOE-H group, and $0.96 \pm 0.09 \mu \mathrm{g} / \mathrm{g}$ in AOE-M group (Figure 2). These data reveal that AOE-H $(p<0.05)$, AOE-M $(p<0.01)$ and POS $(p<0.05)$ significantly increased rat gastric mucus thicknesses, when compared with corresponding value in MOD group. However, the gastric mucosal thickness

Trop J Pharm Res, September 2020; 19(9): 1889 
that resulted from pretreatment with galangin $(0.65 \pm 0.04 \mu \mathrm{g} / \mathrm{g}$ Alcian blue/tissue) did not significantly differ from that in the MOD group. When compared with CON group, AOE-H, AOE$M$ and POS groups showed no statistical differences, indicating that due to pretreatment with $\mathrm{AOE}$ and bismuth potassium citrate, the gastric mucus walls in these groups were not significantly damaged by indomethacin.

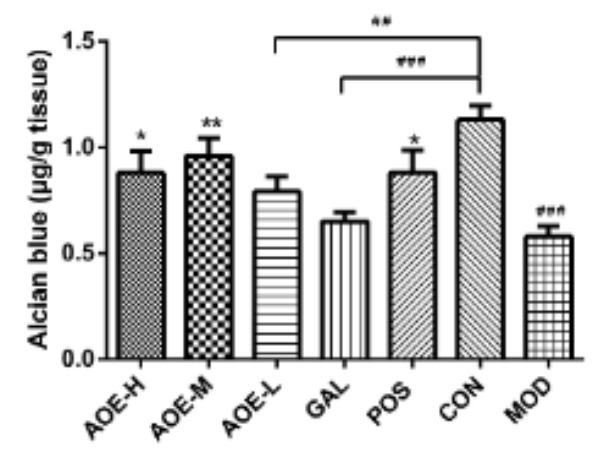

Figure 2: Effects of $\mathrm{AOE}$ and galangin on mucosa thicknesses in acute indomethacin-induced gastric injury rat model. ${ }^{\#} p<0.01,{ }^{\# \#} p<0.001$, vs the CON group; ${ }^{*} p<0.05,{ }^{* *} p<0.01$, vs the MOD group

\section{AOE and galangin inhibited $\mathrm{H}^{+} / \mathrm{K}^{+}$-ATPase activity}

Figure 3 showed the in vivo effects of $A O E$ and galangin on $\mathrm{H}^{+} / \mathrm{K}^{+}$-ATPase activity in acute indomethacin-induced gastric damage rat model. High and medium dose of AOE significantly decreased $\mathrm{H}^{+}-\mathrm{K}^{+}$-ATPase activity by $8.12 \%$ $(p<0.05)$ and $12.19 \%(p<0.01)$, respectively. In contrast, low dose of AOE did not alter $\mathrm{H}^{+}-\mathrm{K}^{+}-$ ATPase activity. Galangin and bismuth potassium citrate significantly decreased $\mathrm{H}^{+} / \mathrm{K}^{+}$ATPase activity by $4.82 \%(p<0.05)$ and $4.70 \%$ $(p<0.05)$, respectively.

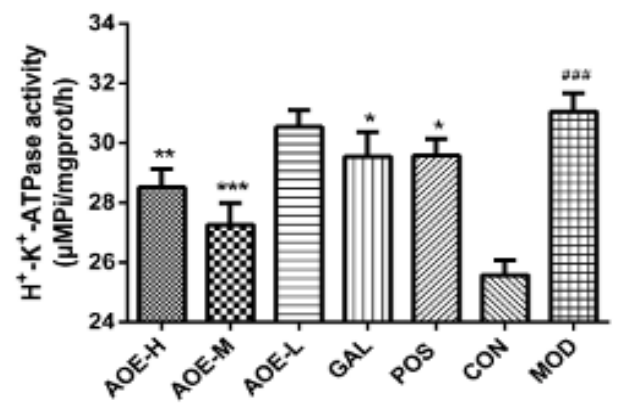

Figure 3: Effects of $A O E$ and galangin on $\mathrm{H}^{+} / \mathrm{K}^{+}$ATPase activity in acute indomethacin-induced rat gastric injury model. ${ }^{\# \#} p<0.001$, vs CON group; ${ }^{*} p<$ $0.05,{ }^{* *} p<0.01,{ }^{* * *} p<0.001$, vs MOD group
AOE, but not galangin, up-regulated EP1 and EP4 protein expressions

The results of Western blot assays for EP1 to EP4 receptors are shown in Figure 4. All EP receptors were suppressed by indomethacin $(p<$ 0.05 or $p<0.01$ ), except EP2 receptor. Upregulations of EP1 receptor were observed in AOE-H $(p<0.05)$ and POS $(p<0.01)$ groups. The expression level of EP4 receptor in AOE-H group was significantly increased, when compared with MOD group $(p<0.05)$. There were no statistically significant differences in EP2 and EP 3 receptor levels when the drug treatment groups were compared with MOD or CON group. Galangin produced no significant effects on EP receptors.

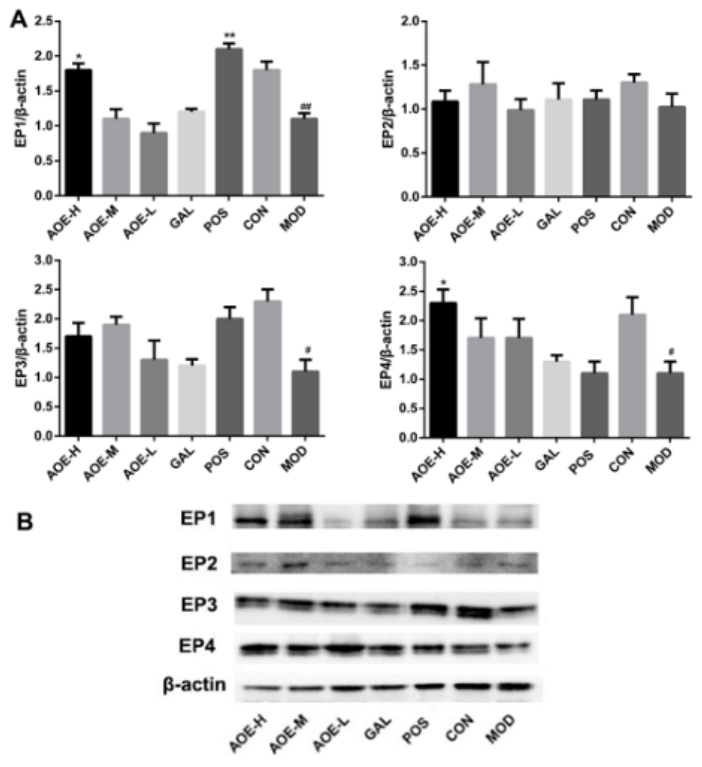

Figure 4: Effects of $A O E$ and galangin on prostaglandin $E_{2}$ receptors in acute indomethacininduced rat gastric injury model. EP: prostaglandin $E_{2}$ receptor. ${ }^{\#} p<0.05,{ }^{\#} p<0.01$, vs CON group; ${ }^{*} p<$ $0.05,{ }^{* *} p<0.01$, vs MOD group

\section{DISCUSSION}

The NSAIDs are widely used as antipyretic, analgesic and anti-inflammatory agents which inhibit cyclooxygenase (COX) activity. However, about $10-25 \%$ of long-term NSAID users develop gastric ulcers, and some may even suffer from gastric bleeding and perforation. Moreover, the pharmacological mechanism associated with NSAIDs is the exact cause of gastric lesions, thereby making it difficult to eliminate the side effects. Cyclooxygenases play important roles in maintenance of gastric mucosal function. Prostaglandins (PGs) derived from COX-1 protect the gastric mucosa from harmful stimuli, while COX-2-derived

Trop J Pharm Res, September 2020; 19(9): 1890 
prostaglandins accelerate the healing of gastric injuries. Indomethacin, which is widely used in producing experimental gastric injury models, suppresses prostaglandin synthesis by inhibiting both COX-1 and COX-2 [11]. Besides, indomethacin also damages the gastric mucosa directly due to its acidic nature. Therefore, acute indomethacin-induced gastric injury rat model was used in this study to reflect topical and systemic actions of NSAIDs. In previous research, the combined effect of $A O E / g a l a n g i n$ and indomethacin was similar to that of selective COX-2 inhibitor (COXIB). However, reports have demonstrated that COXIB treatments impaired the healing of ulcers due to absence of endogenous PGs [12]. Therefore, the gastroprotective effects of $\mathrm{AOE}$ and galangin may be stronger if they are used before indomethacin treatment. Thus, AOE and galangin were given to rats 15 days before acute indomethacin treatment, based on preliminary experiments.

In the pathogenesis of indomethacininduced severe gastric injury, increased gastric acid secretion is a vital event [13].The destruction of gastric mucosal defense is induced by excessive gastric acid, thereby triggering gastric injuries and mucosal barrier collapse[14]. Researchers have found out that $\mathrm{H}^{+} / \mathrm{K}^{+}$-ATPase transports $\mathrm{K}^{+}$into the cell from the extracellular fluid via self-phosphorylation and dephosphorylation, while pumping intracellular $\mathrm{H}^{+}$out of the cell against $\mathrm{pH}$ gradient, thereby controlling gastric acid secretion[16]. Besides, the expression of $\mathrm{H}^{+} / \mathrm{K}^{+}$-ATPase precisely reflects gastric acid secretion [15]. Therefore, $\mathrm{H}^{+} / \mathrm{K}^{+}$-ATPase was used as an index to accurate measurement of the gastric acid secretion of rats in the indomethacin-treated rat model. Drugs which can suppress the $\mathrm{H}^{+} / \mathrm{K}^{+}$-ATPase activity are used in clinical treatment of gastric injury so as to reduce excessive gastric acid.

Data from $\mathrm{H}^{+} / \mathrm{K}^{+}$-ATPase activity assays showed that $A O E$ and galangin inhibited the enzyme to different degrees, which means that excessive gastric acid secretion was under control. Similar results were obtained in some flavonoid studies [7-9]. Therefore, AOE and galangin may regulate gastric acid secretion in indomethacin-induced acute rat gastric mucosa damage model by inhibiting $\mathrm{H}^{+} / \mathrm{K}^{+}$-ATPase. It is worthy of note that the cardiovascular risk associated with NSAIDs and COXIBs has become a concern recently [17]. The US Food and Drug Administration (USFDA) strengthened its warning about the risks of myocardial infarction and stroke due to use of non-aspirin NSAIDs [18]. A meta-analysis has suggested that the combination therapy of COXIB and proton pump inhibitor (PPI) is better than the combined effect of traditional NSAID and $\mathrm{PPI}$ in reducing the risks of recurring gastric bleeding and cardiovascular diseases[19]. The primary function of a $\mathrm{PPI}$ is to inhibit $\mathrm{H}^{+} / \mathrm{K}^{+}$ATPase activity. Thus, $\mathrm{H}^{+}-\mathrm{K}^{+}$-ATPase inhibition may be an important component in the attenuation of COXIB-induced cardiovascular and gastrointestinal diseases. Therefore, the combined use of AOE/galangin and indomethacin may be similar in effect to combination of COXIB and PPI, which may attenuate both cardiovascular and gastrointestinal risks in high risk NSAIDs users. This hypothesis needs to be confirmed through more experiments.

Mucosal defense and vascular perfusion are two defensive factors in gastric mucosal barrier, and they play early and critical roles against NSAIDinduced ulcers. When the basement membrane is exposed due to injury, a "mucoid cap" is formed over the base membrane mucus to protect it. The maintenance of the "mucoid cap" is dependent on uninterrupted mucosal blood flow [20]. The results of neutral red clearance test and gastric wall mucus determination showed that AOE significantly protected the GMBF and mucus thickness from indomethacininduced injuries. Mucus thickness in AOE-M group was close to normal level. Gastric mucosal blood flow in AOE-M group was even higher than that in CON group. These results demonstrate that $A O E$ exerted a strong gastroprotective effect and strengthened gastric mucosal barrier effectively. The AOE-M group produced the best gastroprotective effect, even when compared with the AOE-H group. A possible explanation may be that the pungent property of $\mathrm{DPHC}$, the main component of $\mathrm{AOE}$, constituted a stimulus to the gastric mucosa at the high dose. This weakened the capacity of gastric mucosa defense after 15 days of exposure, resulting in inability to resist indomethacin-induced gastric damage.

The prostaglandin $E_{2}$ receptor is divided into four specific G-protein coupled subtypes i.e. EP 1 EP 4, and its distribution accounts for the multiple effects of prostaglandin $E_{2}[4]$. Reports have demonstrated that prostaglandin $E_{2}$ combines with EP4 receptor to stimulate mucus secretion, and combines with EP1 to stimulate bicarbonate secretion in the stomach[21, 22]. Basal mucosal blood flow is maintained by prostaglandin $E_{2}$ through combining with EP2 or EP 4 receptor.[23]. The healing of gastric ulcer is mediated by prostaglandin $E_{2}$ through its combination with EP4 receptor[16]. Moreover, EP agonists attenuate gastric injuries by reproducing the functions of reduced PGs, while 
EP antagonist significantly eliminate the protective effect of prostaglandin $E_{2}$. The EP agonists improve basal mucosal blood flow, with the exception of EP1 agonists [23]. In addition, the potent protective effect of prostaglandin $E_{2}$ against indomethacin-induced gastric injury can be reproduced by EP1 agonists, but not by other EP agonists [4]. These reports strongly indicate the important roles of prostaglandin $E_{2}$ receptors in suppressing gastric acid secretion and improving thickness of gastric mucus layer and gastric blood flow. Consistent with these findings, AOE improved the EP1 and EP4 receptor levels, suggesting that it may protect the gastric mucosa and improve mucosal blood flow condition by enhancing EP1 and EP4 expressions.

This study has some limitations. The agonists and antagonists of prostaglandin $E_{2}$ receptors should be used subsequent studies to verify the results obtained here. The effects of $A O E$ and galangin on COXIB-induced cardiovascular and gastrointestinal diseases need to be further investigated.

\section{CONCLUSION}

This study demonstrates that the mechanism underlying the gastroprotective effect of ethanol extract of roots of Alpinia officinarum against indomethacin-induced gastric injury involves a combination of multiple targets. The extract inhibited excessive gastric acid secretion by inhibiting $\mathrm{H}^{+} / \mathrm{K}^{+}$-ATPase activity. It increased the GMBF and mucus thickness, and reinforced gastric mucosal barrier by triggering the expressions of prostaglandin $E$ receptor 1 and prostaglandin E receptor 4. Galangin significantly inhibited $\mathrm{H}^{+} / \mathrm{K}^{+}$-ATPase activity and enhanced gastric mucosal blood flow. These findings provide new insights into the mechanisms underlying the gastroprotective effect of Alpinia officinarum, and show its promising potential for clinical use in treating gastric mucosal injury induced by NSAIDs.

\section{DECLARATIONS}

\section{Acknowledgement}

The authors are thankful to Professor Jianping Tian for the identification of plants. This work was supported by the National Natural Science Foundation of China (no. 81560721).

\section{Conflict of interest}

No conflict of interest is associated with this work.

\section{Contribution of authors}

We declare that this work was done by Jingwen Gong, Xuguang Zhang, Yingfeng Tan, Hailong $\mathrm{Li}$, Jie Hou and Junqing Zhang, and all liabilities pertaining to claims relating to the content of this article will be borne by the authors. Junqing Zhang and Jie Hou conceived and designed the study. Jing-wen Gong collected, analyzed the data and wrote the manuscript. Xuguang Zhang and Yinfeng Tan conducted some of the experiments. Hai-long Li participated in the study design and revision of the manuscript.

\section{Open Access}

This is an Open Access article that uses a funding model which does not charge readers or their institutions for access and distributed under the terms of the Creative Commons Attribution License (http://creativecommons.org/licenses/by/ 4.0) and the Budapest Open Access Initiative (http://www.budapestopenaccessinitiative.org/rea d), which permit unrestricted use, distribution, and reproduction in any medium, provided the original work is properly credited.

\section{REFERENCES}

1. Musumba C, Pritchard DM, Pirmohamed M. Review article: Cellular and molecular mechanisms of nsaidinduced peptic ulcers. Aliment Pharmacol Ther 2009; 30(6): 517-531.

2. Rane MA, Foster JG, Wood SK, Hebert PR, Hennekens $\mathrm{CH}$. Benefits and risks of nonsteroidal anti-inflammatory drugs: Methodologic limitations lead to clinical uncertainties. Ther Innov Regul Sci 2019; 53(4): 502505.

3. He H, Li X, Yu H, Zhu S, He Y, Komatsu K, Guo D, Li X, Wang J, Luo $H$, et al. Gastroprotective effect of araloside a on ethanol- and aspirin-induced gastric ulcer in mice: involvement of $\mathrm{H}+/ \mathrm{K}+-$ ATPase and mitochondrial-mediated signaling pathway. J Nat Med 2019; 73(2): 339-352.

4. Takeuchi K, Amagase K. Roles of cyclooxygenase, prostaglandin E2 and EP receptors in mucosal protection and ulcer healing in the gastrointestinal tract. Curr Pharm Des 2018; 24(18): 2002-2011.

5. Shin JM, Munson K, Vagin O, Sachs G. The gastric HKATPase: structure, function, and inhibition. Pflugers Arch 2009; 457(3): 609-622.

6. Gong J, Zhang Z, Zhang X, Chen F, Tan Y, Li H, Jiang J, Zhang J. Effects and possible mechanisms of alpinia officinarum ethanol extract on indomethacin-induced gastric injury in rats. Pharm Biol 2018; 56(1): 294-301.

7. Gupta SS, Azmi L, Mohapatra PK, Rao CV. Flavonoids from whole plant of Euphorbia hirta and their evaluation against experimentally induced gastroesophageal reflux

Trop J Pharm Res, September 2020; 19(9): 1892 
disease in rats. Pharmacogn Mag 2017; 13(Suppl 1): S127-S134.

8. Ribeiro ARS, Valenca JDDN, Santos JS, Boeing T, Silva $L M D$, De Andrade SF, Albuquerquejunior RLC, Thomazzi SM. The effects of baicalein on gastric mucosal ulcerations in mice: Protective pathways and anti-secretory mechanisms. Chem Biol Interact 2016; 260: 33-41.

9. Miyazaki Y, Ichimura A, Sato S, Fujii T, Oishi S, Sakai H, Takeshima $H$. The natural flavonoid myricetin inhibits gastric H+, K+-ATPase. Eur J Pharmacol 2018; 820: 217-221.

10. Clark JD, Gebhart GF, Gonder JC, Keeling ME, Kohn DF. The 1996 guide for the care and use of laboratory animals. Ilar Journal 1997; 38(1): 41-48.

11. Harirforoosh S, Asghar W, Jamali F. Adverse effects of nonsteroidal anti-inflammatory drugs: an update of gastrointestinal, cardiovascular and renal complications. J Pharm Pharm Sci. 2013; 16(5): 821-847.

12. Ma $L$, Soldato $P d$, Wallace JL. Divergent effects of new cyclooxygenase inhibitors on gastric ulcer healing: Shifting the angiogenic balance. Proc Natl Acad Sci U S A 2002; 99(20): 13243-13247.

13. Suleyman H, Albayrak A, Bilici M, Cadirci E, Halici $Z$. Different mechanisms in formation and prevention of indomethacin-induced gastric ulcers. Inflammation 2010; 33(4): 224-234.

14. Salimi A, Neshat MR, Naserzadeh P, Pourahmad J. Mitochondrial permeability transition pore sealing agents and antioxidants protect oxidative stress and mitochondrial dysfunction induced by naproxen, diclofenac and celecoxib. Drug Res (Stuttg) 2019; 69(11): 598-605.

15. Lambrecht NW, Yakubov I, Scott D, Sachs G. Identification of the $k$ efflux channel coupled to the gastric h-k-atpase during acid secretion. Physiol Genomics 2005; 21(1): 81-91.

16. Yao $X$, Forte JG. Cell biology of acid secretion by the parietal cell. Annu Rev Physiol 2003; 65(65): 103-131.

17. Naumov AV, Tkacheva ON, Khovasova NO. Safety of nonsteroidal anti-inflammatory drugs in patients with cardiovascular risk. Ter Arkh 2019; 91: 108-113.

18. Rane MA, Foster JG, Wood SK, Hebert PR, Hennekens $\mathrm{CH}$. Benefits and risks of nonsteroidal anti-inflammatory drugs: Methodologic limitations lead to clinical uncertainties. Ther Innov Regul Sci 2019; 53(4): 502505.

19. Chan FKL, Ching JYL, Tse YK, Lam K, Wong GLH, Ng SC, Lee $V$, Au KWL, Cheong $P K$, Suen $B Y$. Gastrointestinal safety of celecoxib versus naproxen in patients with cardiothrombotic diseases and arthritis after upper gastrointestinal bleeding (concern): An industry-independent, double-blind, double-dummy, randomised trial. Lancet 2017; 389(10087): 2375-2382.

20. Granger DN, Holm L, Kvietys $P$. The gastrointestinal circulation: Physiology and pathophysiology. Compr Physiol 2015; 5(3): 1541-1583.

21. Takeuchi K. Gastric cytoprotection by prostaglandin $E_{2}$ and prostacyclin: relationship to EP1 and IP receptors. J Physiol Pharmacol 2014; 65(1): 3-14.

22. Hosono K, Isonaka R, Kawakami T, Narumiya S, Majima $M$. Signaling of prostaglandin E receptors, EP3 and EP4 facilitates wound healing and lymphangiogenesis with enhanced recruitment of $\mathrm{M} 2$ macrophages in mice. PloS one 2016; 11(10): e0162532.

23. Takeuchi K, Takeeda M, Amagase K, Nakashima M. Regulatory mechanism of the gastric hyperemic response following barrier disruption: Roles of cyclooxygenase-1, the prostaglandin E2/EP1 receptor and sensory neurons. Curr Pharm Des 2015; 21(21): 3002-3011. 